\title{
ANÁLISES DO SOLO E DA MACRÓFITA AQUÁTICA DE UMA REPRESA NUM PARQUE MUNICIPAL EM PATOS DE MINAS-MG
}

Ana Gabriela de Souza Balator Silva- anagabrielasbs@ hotmail.com Centro Universitário de Patos de Minas - UNIPAM

Wagner Marques Oliveira Júnio - wagner1 grupo@ hotmail.com

Centro Universitário de Patos de Minas - UNIPAM

Willian Geraldo da Silva - williang18@ hotmail.com

Centro Universitário de Patos de Minas - UNIPAM

Isabela Ferreira Caixeta- isabelacaixeta31@ @otmail.com

Centro Universitário de Patos de Minas - UNIPAM

Ana Carolina Martins Matos- anacarolinamm@outlook.com

Centro Universitário de Patos de Minas - UNIPAM

Ludimila Lucas da Silva - ludimilalucas@ hotmail.com

Centro Universitário de Patos de Minas - UNIPAM 


\section{RESUMO}

O crescimento da população e a expansão dos maciços urbanos têm acarretado o aumento da poluição por efluentes de diversos tipos, podendo advir de despejos de efluentes domésticos para o solo ou corpos d'água, seja ele legal ou então ilegal, através de canalizações clandestinas. O objetivo deste trabalho consiste em determinar e avaliar, a partir da caracterização foliar da macrófita aguapé (Eichhornia crassipes) e do solo do leito e calha da represa, se há contaminação ambiental do meio, ocasionada por elementos químicos oriundos de práticas da disposição de esgoto doméstico no Parque Municipal do Mocambo Vereador Geraldo Martins, situado em Patos de Minas-MG. Após serem realizadas as análises físico-químicas e comparadas com a Resolução CONAMA n 420 e a Resolução CONAMA n 344 , os resultados encontrados sugerem que o ambiente da represa estudada apresenta tendência à contaminação por Fe, Mn e S, considerando que os elementos citados apresentaram teores mais elevados na folha do aguapé e no solo analisado. Neste contexto, pode-se inferir que existe a prática de descarga de efluente doméstico direta ou indiretamente na represa do Parque em questão.

Palavras-chave: Maciços urbanos, Efluentes, Contaminação, Represa.

\section{INTRODUÇÃO/OBJETIVO}

A partir do crescimento populacional e expansão urbana, a poluição do meio por efluentes de diversos tipos tem-se intensificado. O mesmo pode ser composto por substâncias e elementos, sendo que o efluente, uma vez descartado no ambiente sem um prévio tratamento, pode desencadear a suspensão dessas substâncias na água ou então esses serem sedimentados no leito e calha dos corpos d'água receptores. Desse modo, acarreta não apenas a poluição da água, como também a do solo, afetando as características ambientais das fontes hídricas receptoras, bem como do seu entorno (ALVES et al., 2010).

De acordo com Santos (2002), é determinado pelo Decreto ${ }^{\circ}$ 28.687/82, art. 72, a poluição do solo e do subsolo como sendo a deposição, disposição, descarga, infiltração, acumulação, injeção ou enterramento no solo ou no subsolo de substâncias ou produtos poluentes, sejam eles em estado sólido, líquido ou gasoso.

A poluição do mesmo pode estar ligada a CTC (Capacidade de Troca de Cátions), já que essa capacidade consiste na quantidade total de cátions retidos à 
superfície do solo em condição permutável. Essa poluição pode ser exemplificada pela poluição por metais pesados de solos que já sofreram maior intemperização e são mais velhos, como os solos argilosos, de maneira que esses são compostos em sua maioria por cargas negativas e os metais pesados possuem cargas positivas, fazendo com que o solo atraia esses metais e esses fiquem retidos no solo, contaminando-o (RONQUIM, 2010).

Essa poluição pode advir de despejos de efluente doméstico no corpo d'água, seja ele legal ou então clandestino, através de canalizações que destinam esgoto para o leito ou calha do rio. A partir desse fato, para que essa poluição seja determinada, uma maneira é a realização da análise do solo e macrófitas do corpo d'água sujeito ao despejo de efluente, uma vez que as substâncias contidas no esgoto são retidas tanto pelo solo, quanto pelas raízes das macrófitas.

Assim, o presente trabalho se objetiva em determinar se há contaminação ambiental do meio delimitado - que consiste em uma represa localizada em um parque municipal, ocasionado por elementos químicos oriundos de práticas de disposição de esgoto doméstico, através de analises fotográficas e análises do solo e da macrófita aguapé (Eichhornia crassipes) presentes no local, cujas características podem compor evidencias e assim determinar se há presença de poluentes na água ou solo investigados.

\section{METODOLOGIA}

O estudo de caso foi desenvolvido em uma represa que se encontra no interior do Parque Municipal do Mocambo Vereador Geraldo Martins situado no município de Patos de Minas - MG (Figura 1). 
Figura 1: Localização da área de estudo - Parque Municipal do Mocambo, Patos de Minas / MG.

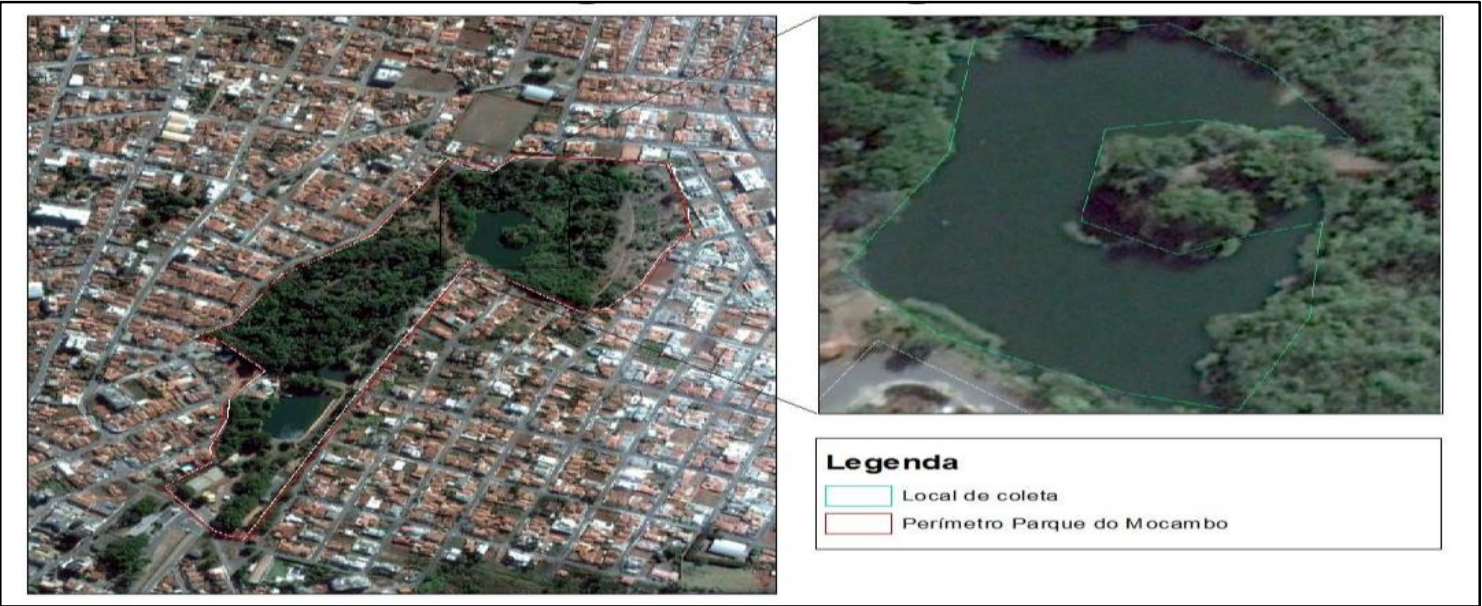

Fonte: Autores, 2016.

O Parque Municipal do Mocambo Vereador Geraldo Martins, criado pela lei $\mathrm{n}^{\circ} 5.293$ - de 29 de maio de 2003, sendo um dos principais cartões postais dessa cidade e tem sido utilizado pela população, gradativamente, para práticas esportivas, recreação e lazer. O referido parque, possui em média 17 há em sua área total, dentro de uma área urbana e contemplado no Plano Diretor como unidade de conservação, serve de manancial de abastecimento e abrigo para animais ali presentes.

\subsection{COLETA E ACONDICIONAMENTO DAS AMOSTRAS}

A coleta de solo e das macrófitas tipo aguapé foram realizadas no dia 27 de setembro de 2016.

Utilizou-se nas coletas alguns materiais como, enxada, mão-de-vaca, pá, invólucros de polietileno e luvas como Equipamento de Proteção Individual (EPI). As amostragens foram realizadas em 3 pontos ao acaso, retirando uma quantidade de solo com a mão-de-vaca a uma profundidade de 0 a 20 e 20 a $40 \mathrm{~cm}$, não foi possível coletar em profundidade maiores devido a afloração d'água. Posteriormente, as amostras foram homogeneizadas a fim de se obter apenas uma amostra composta, totalizando $2 \mathrm{~kg}$ de solo, em que foi acondicionada em um invólucro de polietileno (Figura 2). 
Figura 2: Representação da coleta de amostras de solo (A) presentes no leito e calha da represa e macrófitas aguapé (B) presentes na represa do Parque Municipal do Mocambo Vereador Geraldo Martins, Patos de Minas-MG.
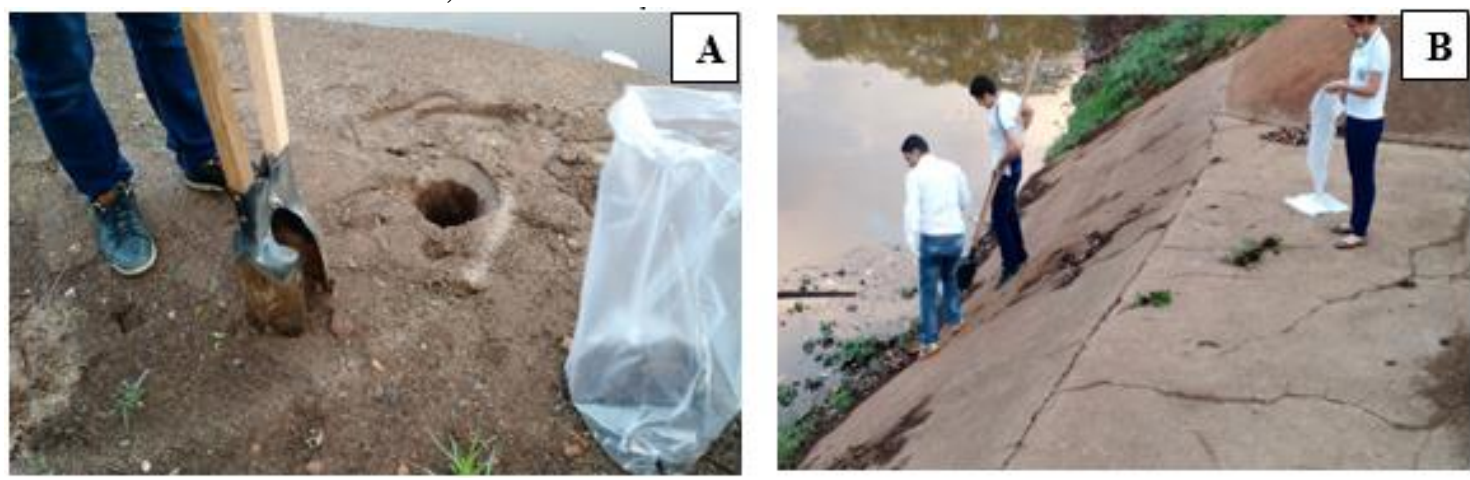

Fonte: Autores, 2016.

Além da amostra de solo (Figura 2A), foram coletadas diversas amostras de aquapés Eichhornia crassipes (Figura 2B) próximas à localidade da coleta de solo, de maneira que tal espécie vegetal estava disposta na margem da represa. Foi utilizada a enxada para recolher os aquapés sem a necessidade de entrar no corpo d'água, aproximando-as da margem, acondicionando todas aquelas recolhidas também em um único invólucro de polietileno

\subsection{ANÁLISE DAS AMOSTRAS}

Após a realização das coletas, as mesmas foram enviadas para o Centro de Análises Terrena, sendo seus procedimentos baseados sistematicamente nas metodologias técnicas e aprovadas pelos mais conceituados órgãos de fiscalização do país, entre eles o PROFERT (solos) e ESALQ (tecido vegetal).

Enviadas com o intuito de analisar parâmetros no solo, como pH (água), Premanescente, Fósforo (P), Potássio (K), Cálcio (Ca), Magnésio (Mg), Alumínio (Al), Cobre (Cu), Ferro (Fe), Manganês (Mn), Zinco (Zn), Enxofre (S), H+Al, SB, Capacidade de Troca Catiônica Efetiva (CTC (t)), Capacidade de Troca Catiônica a pH 7,0 (CTC (T)), Saturação por alumínio (m) e Saturação por bases (V).

A folhas do aquapé também foram submetidas à analises, sendo realizadas no laboratório supracitado, cujos parâmetros referem-se à teores de Nitrogênio $(\mathrm{N})$, Fósforo (P), Potássio (K), Cálcio (Ca), Magnésio (Mg), Enxofre (S), Boro (B), Zinco (Zn), Ferro (Fe), Manganês $(\mathrm{Mn})$ e Cobre $(\mathrm{Cu})$. 


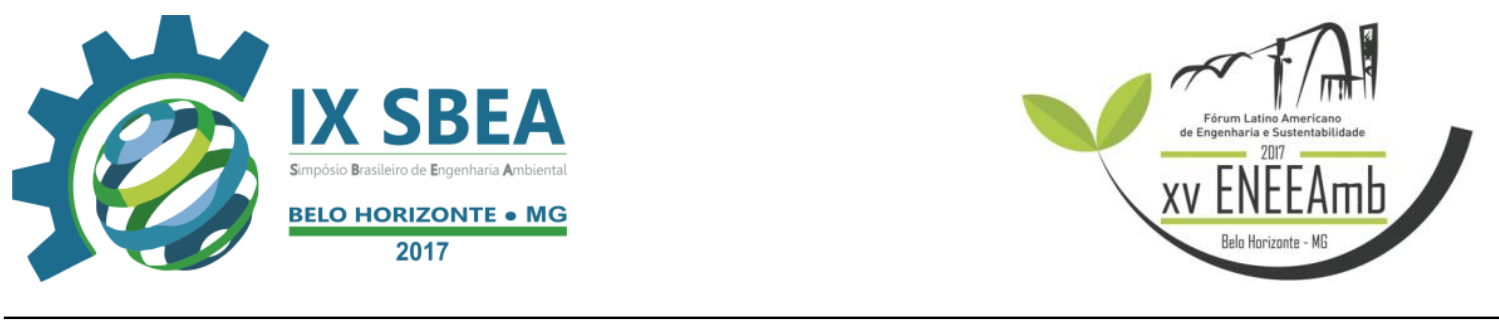

\subsection{ANÁLISE DE DADOS}

Para a análise dos resultados obtidos, utilizou-se a Resolução CONAMA n ${ }^{\circ}$ 420, de 28 de dezembro de 2009, que dispõe sobre critérios e valores orientadores de qualidade do solo quanto à presença de substâncias químicas e estabelece diretrizes para o gerenciamento ambiental de áreas contaminadas por essas substâncias em decorrência de atividades antrópicas assim como da Resolução CONAMA no 344, de 25 de março de 2004, em que se determinam as diretrizes gerais e os procedimentos mínimos para a avaliação do material a ser dragado em águas jurisdicionais brasileiras, e dá outras providências (BRASIL, 2004; BRASIL, 2009).

\section{RESULTADOS E DISCUSSÃO}

Foi realizada diversas visitas in loco para identificar possíveis fontes de lançamento de efluentes dentro do Parque do Mocambo. A Figuras 3 demonstra a situação encontrada no local.

Figura 3 - Disposição inadequada de canos como possíveis fontes de lançamentos de aguas pluviais e efluentes domésticos no equipamento público.

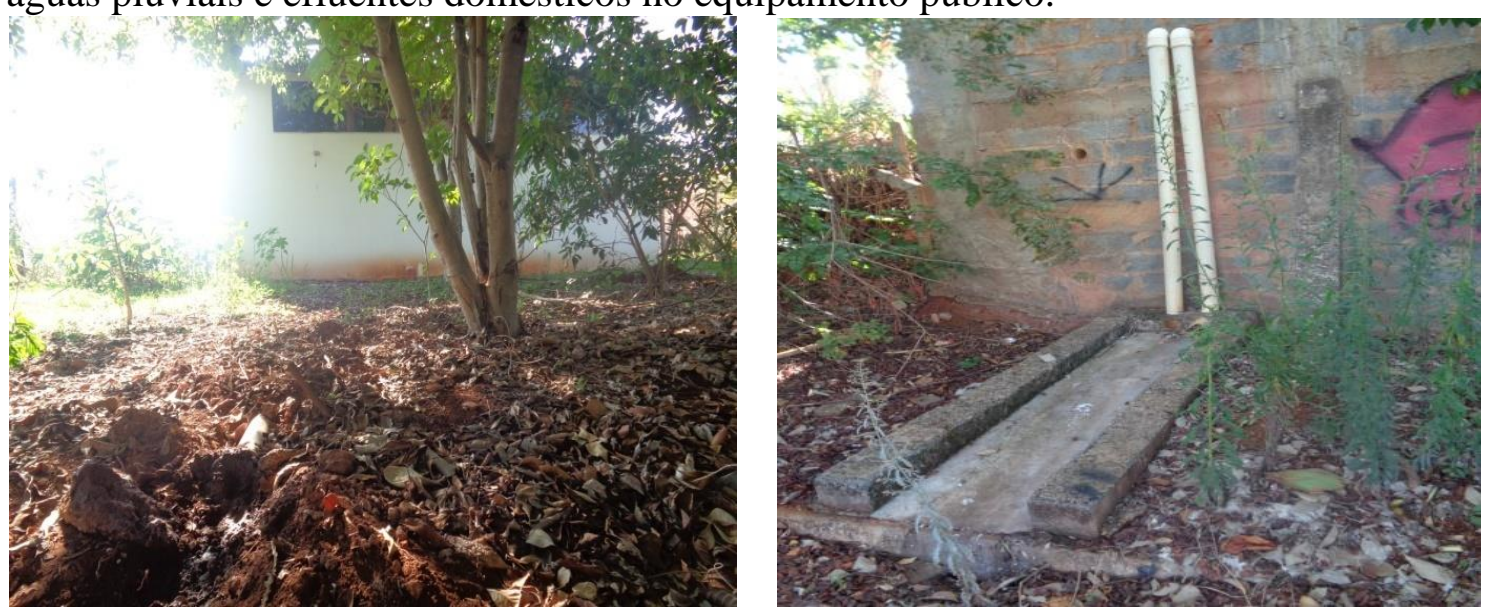

Fonte: Autores, 2016.

As disposições dessas canalizações não se encontram em conformidade de acordo com o Código de Edificações do Município de Patos de Minas que descreve: “O escoamento das águas pluviais deverá ser dirigido para a rede pluvial, mediante canaleta ou tubulação sob os passeios. As edificações não poderão apresentar quaisquer elementos 
salientes que se projetem além do plano do alinhamento das divisas dos lotes confrontantes, inclusive sobre o logradouro público".

Com bases nas premissas advindas das análises fotográficas deu-se início as avaliações físico-químicas do solo para conhecer-se o grau de contaminação advinda das alterações promovidas ao ecossistema aquático. A Tabela 1 apresenta os valores médios para todos os elementos químicos analisados na amostra de solo do corpo hídrico em questão.

Tabela 1 - Níveis dos elementos químicos $\left(\mathrm{mg} \cdot \mathrm{Kg}^{-1}\right)$ de solo da represa situada no Parque Municipal do Mocambo Vereador Geraldo Martins, Patos de Minas-MG.

\begin{tabular}{cccccccccc}
\hline \multicolumn{10}{c}{ Elementos - Concentração no solo $\left(\mathbf{m g . K \mathbf { K g } ^ { - 1 }}\right)$} \\
$\mathrm{P}$ & $\mathrm{K}$ & $\mathrm{Ca}$ & $\mathrm{Mg}$ & $\mathrm{Al}$ & $\mathrm{Cu}$ & $\mathrm{Fe}$ & $\mathrm{Mn}$ & $\mathrm{Zn}$ & $\mathrm{S}$ \\
\hline 37,31 & 30,00 & 4,60 & 0,19 & 0,01 & 6,00 & 125,80 & 67,40 & 24,00 & 101,77 \\
\hline \multicolumn{10}{c}{ Fonte: Autores, 2016.}
\end{tabular}

Soares (2006) explica que o solo será considerado contaminado quando os valores médios dos metais ultrapassarem os valores considerados normais para os solos. Neste sentido, pode-se notar que os teores de Fe, Mn, S e $\mathrm{Zn}$ os caracterizam como àqueles que apresentam as maiores concentrações. Vale destacar que a legislação não apresenta os valores orientadores para solos com relação ao Fe, Mn e Al, devido ao fato de que cada tipo de solo apresenta suas especificações.

Já a tabela 2 apresenta os valores médios para a caracterização dos atributos químicos do solo coletado.

Tabela 2 - Caracterização dos atributos químicos do solo da represa situada no Parque Municipal do Mocambo Vereador Geraldo Martins, Patos de Minas-MG.

\begin{tabular}{cc}
\hline Atributo & Resultados \\
\hline pH água & 7,90 \\
P-rem $\left(\mathrm{mg}^{-1} \mathrm{~L}^{-1}\right)$ & 20,79 \\
$\mathrm{H}+\mathrm{Al}\left(\mathrm{cmol} . \mathrm{Kg}^{-1}\right)$ & 0,89 \\
$\mathrm{SB}\left(\mathrm{cmol} . \mathrm{Kg}^{-1}\right)$ & 4,87 \\
$\mathrm{CTC}(\mathrm{t})\left(\mathrm{cmol} \cdot \mathrm{Kg}^{-1}\right)$ & 4,88 \\
CTC (T) $(\mathrm{cmol.Kg})$ & 5,76 \\
$\mathrm{~m}(\%)$ & 0,21 \\
$\mathrm{~V}(\%)$ & 84,51 \\
\hline
\end{tabular}

Fonte: Autores, 2016. 
O pH, de acordo com Jain (2004), é o principal controlador da solubilidade dos metais. Neste sentido, o pH terá grande influência na liberação dos metais para a coluna de água (GUILHERME et al., 2002). Entretanto, sendo caracterizado como pH básico, o mesmo pode influenciar no aparecimento de altos valores de metais no solo, favorecendo uma maior contaminação que pode oferecer risco de poluição do ambiente aquático. Diferentemente, ao analisarem o solo de uma represa do Município de Viçosa. Soares (2006) verificou que o $\mathrm{pH}$ da água se tratava de um ácido (4,93), fator este que influenciou no aparecimento dos baixos valores de metais no solo, já que possivelmente, os metais adsorvidos tenham sido liberados para a água.

Plantas aquáticas são capazes de remover metais pesados da água através de processos de absorção e bioacumulação, cuja concentração pode ser mil vezes maior que na água onde habitam. (SIVACI et al., 2004). Segundo Wittig (1993), são consideradas como bioacumuladoras, espécies que contém elementos com concentração superior ao ambiente onde estão inseridas e, ainda, com concentração superior à média encontrada em espécies de ambientes não poluídos.

O conhecimento sobre a concentração de metais pesados em diferentes partes das plantas é reduzido, especialmente para as macrófitas aquáticas. As diferentes concentrações de $\mathrm{Cr}, \mathrm{Ni}, \mathrm{Mn}, \mathrm{Fe}, \mathrm{Cu}$ e $\mathrm{Zn}$ nas raízes e folhas indicam que esses metais têm diferentes rotas de absorção e mecanismos de transporte na planta. (SOARES, 2006).

Com relação à concentração de elementos químicos na macrófita aquática utilizada neste estudo, aquapé (Eichhornia crassipes), a Tabela 3 apresenta seus níveis.

Tabela 3 - Níveis dos elementos químicos presentes na amostra foliar de aguapé (Eichhornia crassipes) da represa situada no Parque Municipal do Mocambo Vereador Geraldo Martins, Patos de Minas-MG.

Elementos - Concentração foliar

\begin{tabular}{ccccccccccc}
\hline & - & & & & & \\
\hline $\mathrm{N}$ & $\mathrm{P}$ & $\mathrm{K}$ & $\mathrm{Ca}$ & $\mathrm{Mg}$ & $\mathrm{S}$ & $\mathrm{B}$ & $\mathrm{Zn}$ & $\mathrm{Fe}$ & $\mathrm{Mn}$ & $\mathrm{Cu}$ \\
\hline 25,63 & 3,26 & 21,00 & 17,00 & 4,10 & 2,83 & 13,93 & 203,40 & 53295,00 & 4615,00 & 55,50 \\
\hline
\end{tabular}

Fonte: Autores, 2016.

A espécie Eichhornia crassipes apresentou concentração de todos os elementos reportados para macrófitas aquáticas de ambientes não contaminados. Esse fato sugere que as plantas desta espécie presentes na represa estudada estão removendo os elementos 
da coluna de água, descontaminando o ambiente, cujo resultado também foi observado por (SOARES, 2006).

Para que uma espécie seja considerada como indicadora de contaminação é necessário que a concentração dos metais reflita as condições do ambiente. Neste contexto, as elevadas concentrações de Fe e Mn indicam que o ambiente, como a água, está contaminada por esses elementos químicos, tendo em vista que a análise foliar do aguapé pode representar as características que seu meio se encontra.

Segundo Soares (2006), os íons metais $\mathrm{Cu}^{2+}, \mathrm{Zn}^{2+}, \mathrm{Mn}^{2+}, \mathrm{Fe}^{2+}$ são micronutrientes essenciais para as plantas. Entretanto, quando presentes em excesso, todos esses metais são tóxicos. Nesta perspectiva, há toxicidade desses elementos no ambiente analisado.

Ainda de acordo com Soares (2006), "as plantas aquáticas têm importante papel no sucesso da fitorremediação, não só pela remoção dos poluentes através da absorção dos mesmos, mas também pela capacidade que as mesmas possuem de adsorver e acumular os metais em seus tecidos". Assim, considerando que a fitorremediação é uma das formas mitigadoras atualmente proposta para minimizar os problemas da poluição por metais pesados em sedimento, solo e água, pode-se observar que o aguapé pode ser utilizado como um fitorremediador, tendo em vista seu potencial de planta hiperacumuladora e sua hipertolerância a metais.

\section{CONCLUSÕES/RECOMENDAÇÕES}

Os resultados sugerem que a Eichhornia crassipes é capaz de absorver e acumular metais, apresentando potencial para uso na remoção de poluentes em ecossistemas aquáticos, dependendo da produtividade da biomassa.

$\mathrm{O}$ ambiente da represa estudada apresenta tendência à contaminação por $\mathrm{Fe}, \mathrm{Mn}$ e S, considerando que esses são os elementos que apresentaram os teores mais elevados que se encontravam acumulados na folha do aguapé e no solo analisado, cujos valores podem ser utilizados para se caracterizar o meio em que se localizam.

Neste contexto, pode-se inferir que a prática de descarga de efluentes domésticos está sendo realizada nas mediações ou de forma direta na represa do Parque Municipal 
do Mocambo Vereador Geraldo Martins, tendo em vista os teores de tais elementos químicos encontrados nas análises realizadas.

\section{REFERÊNCIAS BIBLIOGRÁFICAS}

ALVES, R. I. da S.; TONANI, K. A. de A.;NAKAIDO, M.; CARDOSO, O. de O.; TREVILATO, T. M. B.; SEGURA-MUÑOZ, S. I. Avaliação das concentrações de metais pesados em águas superficiais e sedimentos do córrego Monte Alegre e afluentes, Ribeirão Preto, SP, Brasil. Revista Ambiente e Água, v. 5, n 3, 2010. Instituto de Pesquisas Ambientais em Bacias Hidrograficas (IPABHi). Disponível em: <www.ambi-agua.net/seer/index.php/ambi-agua/article/download/286/pdf_360>. Acesso em: out. 2016.

BRASIL. Resolução CONAMA n ${ }^{\circ}$ 344, de 25 de março de 2004. Estabelece as diretrizes gerais e os procedimentos mínimos para a avaliação do material a ser dragado em águas jurisdicionais brasileiras, e dá outras providências. Diário Oficial [da União], 07/05/2004.

BRASIL. Resolução CONAMA n 420, de 28 de dezembro de 2009. Dispõe sobre critérios e valores orientadores de qualidade do solo quanto à presença de substâncias químicas e estabelece diretrizes para o gerenciamento ambiental de áreas contaminadas por essas substâncias em decorrência de atividades antrópicas. Diário Oficial [da União], 30/12/2009.

GUILHERME, L.R.G.; MARQUES, J. J.; PIERANGELI, M. A. P.; ZULIALE, D. Q.; MARCHI, G. Elementos-traço em solos, sedimentos e água. In: Simpósio Nacional sobre Recuperação de áreas degradadas. 5. Belo Horizonte, 2002. Anais... Belo Horizonte, 2002.

JAIN, C.K. Metal fractionation study on bed sediments of river Yamuna, India. Water Res., 38. p.569-578, 2004.

RONQUIM, C. C. Boletim de Pesquisa e Desenvolvimento 8: Conceitos de fertilidade do solo e manejo adequado para as regiões tropicais. Campinas: Embrapa, 2010. 26 p. Disponível em: <http://ainfo.cnptia.embrapa.br/digital/bitstream/item/31004/1/BPD-8.pdf>. Acesso em: 01 out. 2016.

SANTOS, A. S. R. dos; MARTINS, R. de F. Poluição: Considerações ambientais e jurídicas. Revista Imes, São Caetano do Sul, p.97-102, jul/dez. 2002. Disponível em: <http://seer.uscs.edu.br/index.php/revista_direito/article/viewFile/737/597>. Acesso em: out. 2016.

SIVACI, E.R.; SIVACI, A.; SÖKMEN, M. Biosorpotion of cadmium by Myriophyllum spicatum L. and Myriophyllum triphyllum orchard. Chemos, 56:1043-1048, 2004. 
SOARES, C. R. A. Concentração de metais pesados em sedimento, água e macrófitas aquáticas em duas represas do município de viçosa, mg. 2006. $186 \mathrm{f}$. Tese (Doutorado) - Programa de Pós-graduação em Solos e Nutrição de Plantas, Universidade Federal de Viçosa, Viçosa, 2006.

WITTIG, R. General aspects of biomonitoring heavy metals by plants. p.3- 27. In: MARKET, B. (Ed.). Plant as biomonitors - indicators for heavy metals in the terrestrial environmental. Weiheim, VCH, 1993. 644p. 